\title{
A IMPORTÂNCIA DA COMUNICAÇÃO NÃO-VERBAL DO PROFESSOR UNIVERSITÁRIO NO EXERCÍCIO DE SUA ATIVIDADE PROFISSIONAL
}

\author{
The importance of non-verbal communication for teachers \\ in the exercise of their professional activities
}

\author{
Luisa de Fátima Lucena de Sousa ${ }^{(1)}$, Ana Lúcia Leal (2), Ester Feijó Correia de Sena ${ }^{(3)}$
}

\begin{abstract}
RESUMO
Objetivo: verificar a importância da comunicação não-verbal do professor no exercício de sua atividade profissional. Métodos: a presente pesquisa foi realizada no período de março a maio de 2008 . A população de estudo foi composta por alunos de dois cursos de graduação (Ciências Biológicas e de Fonoaudiologia). Foram escolhidos, aleatoriamente, alunos de cada turma, independente de sexo ou idade, compondo um total de 63 alunos. Resultados: os dados obtidos mostraram que, independente da sua formação (se fonoaudiólogo ou não), todos consideraram que a comunicação não-verbal do professor é um importante fator na transmissão das mensagens. Conclusão: a pesquisa mostrou que os entrevistados avaliaram a comunicação não-verbal como importante para a efetividade da interação, podendo interferir no desempenho do docente em sala de aula.
\end{abstract}

DESCRITORES: Comunicação não Verbal; Docentes; Estudantes

\section{INTRODUÇÃO}

A comunicação é uma forma de interação na qual se compartilha idéias, mensagens e sentimentos, podendo ter influência sobre o comportamento das pessoas que, por sua vez, irão reagir a partir de suas crenças, valores, histórias de vida e cultura $^{1}$

O Dicionário Aurélio traz 11 definições para palavra comunicação, com vários sentidos diferentes, entre eles: "a capacidade de trocar ou discutir ideias, de dialogar, de conversar, com vistas ao bom entendimento entre as pessoas" ${ }^{2}$.

Pode-se assegurar que a comunicação é uma ferramenta de trabalho, lazer, relacionamento e

(1) Fonoaudióloga e Bióloga; Secretaria Estadual de Educação, Bom Jardim - PE; Especialista em Morfologia pela Universidade Federal de Pernambuco- UFPE.

(2) Fonoaudióloga e Psicóloga; Prefeitura Municipal de Itapissuma, Itapissuma - PE; Doutoranda em Educação pela Universidade Federal de Pernambuco.

(3) Fonoaudióloga; Prefeitura Municipal de Bom Jardim, Bom Jardim - PE.

Conflito de interesses: inexistente negociação. Sem dúvida alguma é a arma mais poderosa que uma pessoa pode dispor ${ }^{3}$

A comunicação humana não está resumida apenas à linguagem verbal, mas também a uma série de gestos e expressões faciais e corporais que completam a conversação e a tornam mais eficaz. A postura do corpo, as expressões faciais e os gestos esclarecem muito mais sobre o que se está falando do que as próprias palavras.

Considera-se que a competência de ouvir e entender o outro inclui não apenas a fala, mas também às expressões e manifestações corporais. Estes aspectos devem ser enfrentados como elementos fundamentais no processo de comunicação e, por isto, acredita-se que o estudo da comunicação não-verbal (linguagem corporal) deveria assumir um papel importante na decodificação das mensagens vivenciadas durante 0 processo de interação ${ }^{4}$

A linguagem não-verbal não é feita nem por sinais verbais nem pela escrita. Este tipo de linguagem é constituída por gestos, tom de voz, postura corporal, etc. Ela está mais enraizada em nosso passado biológico, sendo também a mais primária, intuitiva, praticamente não obedecendo à vontade. Por isso, 
ela é menos sujeita às influências e, de certa forma, muitas vezes, faz com que contradiga o que está sendo dito através de palavras.

É a representação natural das atitudes e ações do homem, expondo os sentimentos e percepções que o indivíduo conhece em um dado momento ${ }^{5}$. Para Silva ${ }^{6}$, por sua espontaneidade e difícil controle, é vista como exata, manifestando intenções que, na maioria das vezes, não se deseja ou se pode exprimir.

A linguagem não-verbal configura-se como um expressivo meio de comunicação. O corpo é cheio de significados, sendo este o responsável pela relação do indivíduo na sociedade, com ele somos capacitados a perceber e a sentir determinados comportamentos. Quando os indivíduos se comunicam, todo o corpo se comunica junto, pois as mensagens da comunicação não-verbal podem demonstrar sentidos peculiares, confirmar a mensagem verbal ou, ainda, noticiar outras mensagens.

Quando uma pessoa gosta de outra, sinaliza-o primeiro, através de sinais não-verbais e depois por mensagens verbais. As mensagens não-verbais podem, da mesma maneira, destruir relacionamentos interpessoais, pois o corpo, ao propagar seu ser sensível, torna-se transporte e meio de comunicação com o mundo, onde as revelações desencadeadas levam o homem a desvendar-se de forma evidente. $\mathrm{E}$, frequentemente, a comunicação não-verbal modifica o sentido da verbal, ou seja, a mensagem verbal às vezes é incoerente ao que é anunciado pela comunicação não-verbal ${ }^{1,7,8}$.

A forma de comunicação não-verbal, portanto, ganha grande valor, pois, esta pode aprovar ou negar a mensagem transmitida através da expressão verbal e também pelo fato desta estar sempre presente, esteja a comunicação verbal sendo emitida ou não $0^{9,10}$.

A comunicação não-verbal, composta pela aparência física, movimentos e expressões corporais, exerce um enorme papel na comunicação e, portanto, no relacionamento humano. Sendo assim, reconhecimento da existência e do valor de um modo não-verbal, que se expressa através do corpo e do movimento do ser humano, ao lado do verbal, é de suma importância para profissionais que interagem com pessoas no seu dia a dia ${ }^{11}$.

A importância da expressividade no processo de aprendizagem é um tema que já vem sendo estudado e debatido há muito tempo na área da pedagogia e psicologia. Os aspectos emocionais, como raiva ou depressão (tanto do aluno como do professor), impedem que alunos apreendam informações com eficiência. Dentro desta expectativa, essa questão deve ser entendida tanto pelo professor, quanto pelo aluno. Docentes experientes buscam perceber de forma especializada os estados emocionais dos alunos e, a partir desta observação, tomar alguma atitude que permita impactar positivamente no aprendizado ${ }^{12}$.

No cotidiano escolar, alguns alunos se queixam de que a comunicação não-verbal do professor favorece a desatenção em sala de aula, tornando a comunicação pouco efetiva. É possível que isto aconteça porque poucos professores sabem da importância da sua linguagem não-verbal no processo de transmissão de conhecimentos.

Nesse sentido, supõe-se que poucos professores têm consciência da importância de sua comunicação não-verbal para o pleno exercício de sua profissão, e acredita-se que se esta comunicação não ocorrer de modo efetivo poderá, de fato, comprometer a atenção que o aluno dará ao conteúdo transmitido. Por este motivo, entendese que uma adequada comunicação não-verbal é fundamental, pois pode contribuir para melhorar o desempenho do docente em sala de aula.

Acredita-se que a comunicação deva ser natural, sem exageros, podendo favorecer a credibilidade na transmissão dos conteúdos. Imagina-se, portanto, que uma adequada comunicação não-verbal do professor poderá contribuir para o processo de aprendizagem dos alunos, que contarão com mais um facilitador para a compreensão dos conteúdos transmitidos.

Motivado por estas questões, o presente trabalho teve como objetivo verificar a importância da comunicação não-verbal do professor no exercício de sua atividade profissional entre graduandos de dois cursos universitários.

\section{MÉTODOS}

O estudo foi considerado descritivo, observacional, transversal. Tratou-se de um estudo seccional.

O estudo foi realizado com os alunos dos cursos de graduação em Licenciatura Plena em Ciências Biológicas e em Fonoaudiologia. A pesquisa foi realizada no período de março a maio de 2008.

A amostra inicial da pesquisa envolvia a escolha aleatória de uma população de 10 alunos de cada período do curso de graduação. No total, participaram da presente pesquisa 63 alunos.O critério mínino de escolha foi ser aluno regular da graduação e não portador de alguma deficiência que venha a prejudicar sua comunicação.

A coleta dos dados foi realizada utilizando-se um questionário elaborado pela autora. acompanhados do Termo de Compromisso Livre e Esclarecido - TCLE, onde os participantes foram infor- 
mados quanto ao teor da pesquisa e seus objetivos e convidados a participar.

O protocolo aplicado constou de quatro perguntas objetivas e subjetivas, nas quais foram questionados sobre a importância da comunicação não-verbal do docente em seu desempenho profissional. Os questionários foram aplicados durante o intervalo dos alunos. Estes eram convidados individualmente a uma sala reservada, na qual tiveram uma maior privacidade para responder 0 questionário.

Para transcrever os resultados obtidos na pesquisa dos dados objetivos foi utilizado $O$ software EPIINFO. Foi criado um banco de dados no Microsoft Excel, onde se realizou a transcrição dos mesmos em dados numéricos, para se evitar erros.

Antes do início da coleta de dados o presente projeto foi previamente submetido ao Comitê de Ética em Pesquisa com Seres Humanos da Universidade Federal de Pernambuco para apreciação e posterior autorização, tendo obtido o registro: CEP/ CCS/UFPE № 329/07.

\section{RESULTADOS}

Os resultados mostraram que todos os entrevistados consideraram que a comunicação não-verbal do professor é um importante fator para a transmissão das mensagens. Os entrevistados relataram que esta forma de comunicação complementa as informações verbais, demonstrando mais verdadeiramente o que se pensa ou sente.

Foi observado também que $77 \%$ dos alunos entrevistados consideraram que a comunicação não-verbal do professor interfere em seu aprendizado, enquanto $23 \%$ mencionaram não interferir. Dos que consideram interferir, houve comentários de que "o corpo fala" e que este demonstra o interesse do professor no assunto. Acreditam que os gestos complementam a fala, ajudando na interpretação do que é dito. Os entrevistados relataram também que através da expressividade corporal pode-se evidenciar segurança, entusiasmo sobre o assunto debatido, podendo tanto atrair a atenção ou quanto a dispersão do aluno durante a aula.

\section{DISCUSSÂO}

Todos os entrevistados consideraram que a comunicação não-verbal do professor é um importante fator na transmissão de mensagens, apontando que, independente da formação (se fonoaudiólogo ou não), houve um reconhecimento da importância desta forma de comunicação. Como os questionários apresentaram perguntas subjetivas, houve um espaço para o voluntário exprimir sua opinião sobre o referido assunto, e sendo assim, eles relataram que a comunicação não-verbal complementa as informações verbais, demonstrando mais verdadeiramente o que pensamos ou sentimos. Isto condiz com os resultados de Oliveira ${ }^{10}$, quando ele comenta que a comunicação não-verbal pode divulgar o que se tem em mente através do corpo, gestos, comportamentos e atitudes, muito mais do que se gostasse ou se desejasse dizer. Silva ${ }^{6}$ complementa que, por sua espontaneidade e difícil domínio, a comunicação não-verbal é vista como verdadeira por manifestar as verdadeiras intenções.

Também foi mencionado que através da expressividade do corpo pode-se perceber se o professor está seguro e entusiasmado com o tema abordado, favorecendo ou não a atenção do aluno. Isto condiz com os estudos de Araújo et $a^{13}$, que acreditam que a comunicação não-verbal é dada pelo tom da voz e pela maneira com que as palavras são expressas, por olhares e expressões faciais, por gestos que acompanham o discurso, pela postura corporal, pelo tamanho da distância física que as pessoas mantêm umas das outras e até mesmo por suas roupas e acessórios, podendo estes, de modo inadequado, chamar mais a atenção do ouvinte do que para o conteúdo da conversa.

\section{CONCLUSÃO}

A presente pesquisa demonstrou que a maioria dos entrevistados, independente de estar inserido no curso de Fonoaudiologia, sugerindo a comunicação não-verbal como um importante fator para a efetividade comunicativa, podendo interferir no desempenho do docente em sala de aula. Porém novas pesquisas com uma amostra mais abrangente seria importante para consolidar tais resultados.

Diante disso, recomenda-se uma maior atenção por parte dos professores, para que, ao perceberem que sua comunicação corporal tem interferido negativamente na aprendizagem de seus alunos, possa buscar sua superação e aperfeiçoamento, favorecendo, deste modo, um melhor desempenho em sua atividade profissional. 


\begin{abstract}
Purpose: to check the importance of non-verbal communication for teachers in the exercise of their professional activities. Methods: this research was conducted during the period from March to May, 2008. The studied population was made up of students from the two under-graduation courses the (Biological sciences and speech therapy). They were chosen randomly, 63 students, regardless of gender or age. Results: data obtained showed that, regardless of their training (whether or not speech therapist), everybody considered that the non-verbal communication of the teacher is an important factor in the transmission of messages. Conclusion: the research showed that the investigated students and teachers evaluated the non-verbal communication as important for the effectiveness of interaction and can interfere in the performance of teachers in the classroom.
\end{abstract}

KEYWORDS: Non-verbal Communication; Faculty; Students

\section{REFERÊNCIAS}

1. Silva, LMG. da et al Comunicação não-verbal: reflexões acerca da linguagem corporal. Rev. latino-am.enfermagem. Ribeirão Preto, agosto 2000; 8(4):52-8.

2. Ferreira A.B.H. Mini Dicionário Aurélio Escolar. Rio de Janeiro: Nova Fronteira, 2001, 790 p.

3. Ladeira, MAT;Darido,SC. Educação Física e Linguagem: Algumas considerações iniciais. Motriz. Rio Claro, Janeiro/Abril,2004;9(1):31-9.

4. Cotes, C;Ferreira,LP. Voz e gesto em telejornalismo. Rev da Socied Bras de Fonoaudiologia. São Paulo,2001; 6(1):29-38.

5. Silva, I. L. e et al. Percebendo o corpo que aprende: considerações teóricas e indicadores para avaliação da linguagem não-verbal de escolares do 10. ciclo do ensino fundamental. Ensaio: aval das políticas públ Educ. Rio de Janeiro, outubro/ dezembro,2004; 12(45): 995-1012.

6. Lemos, I.S. A comunicação não-verbal: Um estudo de caso. UNIrevista. Porto Alegre, 2006;1(3);1-12.

7. Guairsa, JA. O corpo fala? Motriz. São Paulo,Setembro/Dezembro, 2004;8(3):85-90
8. Santos, C. C. V.; shiratori, K. A influência da comunicação não verbal no cuidado de enfermagem. Rev Bras de Enfermagem. Brasília, 2005;58(4):434-7.

9. Oliveira S. C. Estudos de Psicologia e Filosofia. 4 ed. Rev. Rio de Janeiro, 2007;196p. Disponível em: //http:// www.sexodrogas.pcs.br. Acesso em: 19 Setembro 2008.

10. Mesquita, R. M. Comunicação nãoverbal:relevância na atuação profissional,

Rev Paul Educação Física, São Paulo, jullho/ dezembro, 1997,11(2): 155-63.

11. Machado, F. B.; Miranda,L. L. O uso do construtivismo e da afetividade nas metodologias de ensino à distancia. 2006. Trabalho de conclusão de curso. (Especialização). Pontifica Universidade Católica, Rio de Janeiro:2006. 80 p.

12. Araújo MMT, Silva MJP, Puggina ACG. A comunicação não-verbal enquanto fator iatrogênico. Rev Escola Enferm USP. 2007; 41(3):419-25.

13. Ferreira ET AL. Professores em contexto profissional e não profissional: análise objetiva e subjetiva dos aspectos da articulação e da postura. DistúrbiosdaComunicação. Rev. Dist. Comunicação. São Paulo. Agosto,2006;18(2):179-188.

DOI: 10.1590/S1516-18462010005000088

RECEBIDO EM: 01/09/2009

ACEITO EM: 26/01/2010

Endereço para correspondência

Luisa de Fátima Lucena de Sousa

Av. Presidente Castelo Branco, 205

Bom Jardim - PE

CEP: $55730-000$

E-mail: Luisasousa13@yahoo.com.br 